SISTEMA
ELETRÔNICO
DE REVISTAS
SER I UFPR

\title{
Políticas públicas de pagamento por serviços ambientais para a conservação dos recursos hídricos: origens, atores, interesses e resultados da ação institucional
}

\section{Public policy of payment for environmental services for the conservation of water resources: origins, actors, interests and results of institutional action}

\author{
Rafael Eduardo CHIODI ${ }^{*}$, Paulo Eduardo Moruzzi MARQUES ${ }^{2}$ \\ ${ }^{1}$ Departamento de Administração e Economia, Universidade Federal de Lavras (UFLA), Lavras, MG, Brasil. \\ ${ }^{2}$ Departamento de Economia, Administração e Sociologia Rural, Escola Superior de Agricultura "Luiz de Queiroz" (ESALQ), Universidade \\ de São Paulo (USP), Piracicaba, SP, Brasil. \\ *E-mail para contato: rafaelchiodi@gmail.com
}

Artigo recebido em 4 de outubro de 2016, versão final aceita em 21 de março de 2018.

\begin{abstract}
RESUMO: O presente artigo faz uma análise de diferentes aspectos relacionados aos atores e às instituições responsáveis pela existência de três importantes projetos públicos de pagamento por serviços ambientais para a conservação dos recursos hídricos. Além disso, propõe compreender em que medida estes projetos contribuem para reconhecer e valorizar a multifuncionalidade da agricultura familiar. Para tanto, realizou-se o estudo de caso dos seguintes projetos: ProdutorES de Água (Espírito Santo), Conservador das Águas (Minas Gerais) e Projeto Piloto (São Paulo). Nestes casos, os formuladores, os gestores e os executores dos projetos foram entrevistados. As origens dos projetos mostraram que derivaram da presença de três elementos centrais: capacidade técnica, interesse político e aporte financeiro. A existência destes elementos foi possível graças à atuação de diferentes atores técnicos, políticos e parceiros. Os interesses que moveram suas ações estiveram centrados na visibilidade política e institucional, no acúmulo de expertise ambiental e no intuito da restauração florestal, constituindo também os principais resultados alcançados pelos projetos. No entanto, apesar de seus objetivos de reconhecer, incentivar e apoiar proprietários rurais pela e para a conservação ambiental, não foi esta perspectiva que motivou os atores. Assim, além das dimensões sociais, econômicas e culturais da população rural terem sido em grande medida desconsideradas, com o privilégio da dimensão estritamente ambiental, esta última parece também não ter sido adequadamente tratada. De todo modo, são os significativos resultados institucionais alcançados que permitem explicar o profundo engajamento dos atores para empreenderem tais projetos.
\end{abstract}


Palavras-chave: agricultura familiar; água; serviços ambientais; política pública.

ABSTRACT: This article analyzes different aspects related to actors and institutions responsible for the existence of three major public projects for payment for water conservation services. Moreover, this study regards to what extent these projects contribute to recognize and value the multifunctionality of family farming. For such purpose, a case study of the following projects was carried out: ProdutorES de Água (Espírito Santo), Conservador das Águas (Minas Gerais) and Projeto Piloto (São Paulo). In these cases, project makers, managers and implementers were interviewed. The origins of these projects showed that they derived from the presence of three main elements technical, political interest and financial support. The existence of these elements was made possible due to the work of different technical actors, politicians and partners. The interests that moved their actions were focused on political and institutional visibility, the environmental expertise accumulation and aimed at forest restoration, as well as being the main results achieved by the projects. Although the actors aimed to recognize, encourage and support farmers by and for environmental conservation, that was not the perspective that motivated actors. Thus, in addition to social, economic and cultural dimensions of the rural population being largely ignored, with the privilege of strictly environmental dimension; the latter also seems to have not been treated properly. Nevertheless, significant institutional results achieved allow us to explain the deep engagement of actors to undertake such projects.

Keywords: family farming; water; environmental services; public policy.

\section{Introdução}

O termo serviços ambientais diz respeito às intervenções humanas que favorecem as condições e os processos pelos quais os ecossistemas mantêm suas funções e sustentam a vida (Daily, 1997). Em 2005, com a publicação da Avaliação dos Ecossistemas do Milênio (The Millennium Ecosystem Assessment - MEA), a noção de serviços ambientais entrou na agenda política internacional. Na última década, esta noção passou a ser um referencial para a formulação de novos instrumentos para a conservação ambiental, em especial, o pagamento por serviços ambientais (PSA) (Bonnal et al., 2012).

O PSA foi apresentado como um mecanismo baseado no mercado para o financiamento da conservação (Engel et al., 2008). No entanto, por ser um instrumento contratual e versátil, houve possibilidade de ser incorporado em distintas concepções de formatação de política pública. Em termos gerais, o PSA pode ser definido como uma transferência de recursos entre atores sociais, a qual objetiva criar incentivos para alinhar decisões individuais ou coletivas de uso da terra com o interesse social na gestão de recursos naturais (Muradian et al., 2010).

No Brasil, o PSA para a conservação dos recursos hídricos (PSA-Água) foi recentemente adotado pelas políticas públicas (Pagiola et al., 2013). Neste âmbito, diferentes dispositivos estabelecem por meio de contrato uma transferência monetária a agentes que promovam ações de conservação dos serviços ambientais. Com efeito, os proprietários de imóveis rurais se tornam o público privilegiado destas políticas.

A maior parte das iniciativas consolidadas de PSA-Água ocorrem na região Sudeste (Pagiola et al., 2013). Estas iniciativas se orientam pelo "Programa Produtor de Água" da Agência Nacional de Águas (ANA), que estabelece como uma de suas diretrizes a sua aplicação em áreas rurais, visando 
preferencialmente, pequenos produtores (ANA, 2013). Até 2013, praticamente todas as principias iniciativas de PSA-Água envolviam pequenos produtores (Pagiola et al., 2013).

Por alçar a agricultura familiar como público-alvo destas políticas, o mecanismo de PSA-Água vem atraindo o interesse de pesquisadores, gestores públicos, organizações não governamentais e movimentos sociais envolvidos com o desenvolvimento rural. A partir desta leitura, a noção de multifuncionalidade da agricultura (MFA) nos pareceu fecunda para a análise de projetos de PSA-Água.

Para Sabourin (2005), a MFA pode ser caracterizada como o reconhecimento pela sociedade do interesse público de funções sociais, ambientais, econômicas e culturais - não diretamente produtivas - associadas à atividade agropecuária. Para Maluf (2002), o enfoque da MFA é tomado como um "novo olhar" sobre a agricultura familiar que extrapola seu caráter setorial e incorpora a provisão de bens públicos relacionados ao meio ambiente, à segurança alimentar e ao patrimônio cultural. Assim, tal enfoque passou a disponibilizar um instrumental teórico-metodológico para analisar contextos rurais e novas políticas públicas para a agricultura (Carneiro \& Maluf, 2003).

Desse modo, o presente artigo apresenta uma análise de diferentes aspectos relacionados aos atores e às instituições responsáveis pela existência de três importantes projetos de PSA-Água. A intenção consiste em compreender em que medida estes projetos permitem reconhecer e valorizar a multifuncionalidade da agricultura familiar. Para tanto, o artigo se estrutura da seguinte maneira: a seção 2 trata da sustentação teórico-metodológica da pesquisa, apresentando as vinculações entre o referencial da multifuncionalidade da agricultura e o de serviços ambientais; a seção 3 diz respeito à metodologia empregada na pesquisa; na seção 4, são apresentadas as origens dos projetos a partir de suas trajetórias de implementação; na seção 5, os atores responsáveis e seus papéis nos cenários dos projetos são identificados; na seção 6, são discutidos os interesses que motivaram os atores a construírem os projetos; na seção 7, os principais resultados ambientais e institucionais alcançados são discutidos e, por fim, nossas considerações finais são apresentadas.

\section{Multifuncionalidade da agricultura e serviços ambientais: a convergência de referenciais}

No campo da análise de políticas públicas, a abordagem cognitiva é uma corrente de estudos que enfatiza o papel das ideias, das representações sociais e da aprendizagem no processo de formulação das políticas públicas (Grisa, 2011). Nesta corrente, o conceito de "referencial" de política pública é central, tal como proposto pelos autores franceses Bruno Jobert \& Pierre Muller (1987). A perspectiva dos "referenciais" permite conceber as políticas públicas como uma expressão das representações que uma sociedade ou um grupo social tem da realidade (Muller, 2002). Neste sentido, a formulação de uma política pública se torna um processo de mediação social que será embasado por uma representação da realidade sobre a qual se deseja intervir. É com este "referencial de política pública" que os atores sociais interpretarão os problemas, confrontarão as soluções e definirão suas ações (Muller, 2002).

Para Muller (2002), há um referencial global, que é uma representação geral em torno da qual se 
ordenam e se hierarquizam as diferentes representações setoriais. Trata-se de um quadro geral de interpretação do mundo que supera os limites de um setor, de um domínio, ou de uma política. Nesta abordagem, há também um referencial setorial, que é a representação do lugar e do papel de um setor numa sociedade numa época determinada. $\mathrm{O}$ referencial setorial se articula efetivamente com o referencial global.

Conforme Mormont (2015), o referencial não se resume a uma representação ideológica, mas se traduz em dispositivos concretos que delimitam as ações. Neste sentido, o referencial produz categorias de percepção do mundo social e do mundo natural. $\mathrm{O}$ referencial global deve acomodar-se à diversidade dos mundos reais aos quais ele se direciona, e que a ele resistem. Assim, o referencial elabora compromissos com os mundos e surgem novas categorias intermediárias que permitem conciliar as ambições de ambos.

Nesta linha de pensamento, o desenvolvimento sustentável ${ }^{1}$ pode ser entendido como um referencial global que emergiu nos últimos anos e que passou a orientar a formulação de novas políticas públicas. No entanto, deste referencial global surgiram distintos referenciais setoriais: multifuncionalidade da agricultura (MFA) e serviços ambientais (SA).

A MFA emerge com a construção de uma visão de mundo que considera a agricultura como comportando múltiplas dimensões de interesse para a sociedade (social, econômica, ambiental e cultural) e para o meio rural, não exclusivamente pelo seu componente produtivo e econômico (Maluf, 2002). Logo, as políticas públicas que emergem deste refe- rencial devem legitimar a percepção do agricultor como um ator social que desempenha vários papeis na sociedade (Carneiro \& Maluf, 2003).

Por outro lado, o referencial de SA é construído a partir de uma visão de mundo cujo foco se dirige às relações entre sociedade e ecossistemas (MEA, 2005). Nesta ótica, a sociedade depende dos ecossistemas, ou melhor, dos serviços que os ecossistemas fornecem aos seres humanos. A MEA definiu quatro tipos de serviços ecossistêmicos, que envolvem fatores econômicos, sociais, ambientais e culturais, a saber: provisão (alimentos, água potável, combustíveis), suporte (ciclagem de nutrientes, formação dos solos e produção primária), regulação (regulação do clima, purificação da água, controle de doenças) e culturais (espiritual, educacional e recreacional) (MEA, 2005). Na medida em que os ecossistemas estão sendo rapidamente degradados, considera-se que há uma limitação das possibilidades futuras de desenvolvimento desta sociedade (MEA, 2005). Logo, este referencial embasa novas políticas públicas que visam manter, recuperar e aumentar a provisão de serviços ambientais de interesse da sociedade. Devido à íntima relação entre meio ambiente (ecossistemas) e meio rural, muitas das políticas públicas inovadoras concebidas com este referencial recaem sobre o agricultor, a atividade agrícola e o espaço rural.

No entanto, apesar da convergência destes referenciais, são os atores em torno de sua operacionalização que determinarão os enfoques das políticas públicas. Conforme Mormont (2015), convém se interessar mais pelos dispositivos e pelos instrumentos que emergem de determinado referencial.

\footnotetext{
${ }^{1}$ Conforme Sachs (2004), está associado ao compromisso com a ética e a solidariedade para com as gerações presentes e futuras no que tange a utilização sustentável dos recursos naturais, estabelecendo critérios de sustentabilidade social, ambiental e econômica.
} 
Neste sentido, entende-se que as políticas públicas estão relacionadas à ação dos governos, mas cada vez mais os seus processos de formulação e de implementação se abrem à participação de indivíduos, grupos ou organizações externos à esfera estatal (Massadier, 2011). Muller (2002) chama estes atores de "mediadores da política pública". Provenientes de diferentes grupos (agricultores, industriais, ambientalistas), "os mediadores são os responsáveis por tornar inteligível aos demais atores a relação global/setorial e por traduzir esta relação em termos de ação concreta, de normas e de critérios de intervenção pública" (Jobert \& Muller, 1987 apud Grisa 2011, p. 101). Desse modo, "os referenciais são, simultaneamente, constrangimentos estruturais e o resultado do trabalho sobre os sentidos efetuados pelos atores" (Grisa, 2011, p. 101). Assim, os interesses dos atores que desempenham o papel de concepção e gestão das políticas públicas ganham importância (Muller, 2002). Portanto, os interesses dos atores influenciam o modo como os referenciais são mobilizados (Grisa, 2011).

\section{Metodologia}

A pesquisa focou três projetos de PSA-Água implementados por diferentes esferas públicas nos estados de São Paulo, Minas Gerais e Espírito Santo.

A nível estadual, a pesquisa focou o projeto ProdutorES de Água, em Alfredo Chaves/ES município predominantemente rural cuja principal forma de organização produtiva é a agricultura familiar. Foi neste município que o projeto ProdutorES de Água foi pioneiramente implementado pela Lei Estadual no 8.995 de 23 de setembro de 2008. Tal lei prescreve como objetivo do PSA recompensar financeiramente o proprietário rural em função do valor econômico dos serviços ambientais prestados por sua área de cobertura florestal (Espírito Santo, 2008).

A nível municipal, a pesquisa abordou o Conservador das Águas no município de Extrema no sul de Minas Gerais - município cujo meio rural é marcado pela presença de agricultores familiares e neorurais. Neste caso, a Lei Municipal 2.100, de 21 de dezembro de 2005 foi homologada, o que permitiu a criação do projeto Conservador das Águas. A lei tem como objetivo a implantação de ações para a melhoria da qualidade e quantidade das águas no município de Extrema por meio do apoio financeiro aos proprietários rurais (Extrema, 2005).

A nível do Comitê de Bacia Hidrográfica, pesquisou-se o Projeto Piloto Produtor de Água no Comitê das Bacias Hidrográficas dos Rios Piracicaba, Capivari e Jundiaí (Comitê PCJ), nos municípios de Joanópolis e Nazaré Paulista, em São Paulo - municípios predominantemente rurais que abrigam agricultores familiares e neorurais. $\mathrm{O}$ Projeto Piloto Produtor de Água no PCJ foi viabilizado pela Deliberação dos Comitês PCJ n ${ }^{\circ} 51 / 06$, que permitiu o uso de recursos da cobrança pelo uso da água nas Bacias PCJ para o PSA. O objetivo do projeto é aplicar o modelo provedor-recebedor, incentivando os proprietários rurais a contribuírem com a proteção e recuperação dos mananciais através de pagamentos financeiros (ANA, 2013).

Como técnicas de obtenção de dados, foram usadas a documentação indireta, composta pela pesquisa documental e bibliográfica, e a documentação direta, composta pela pesquisa de campo (Lakatos \& Marconi, 1991).

A pesquisa de campo ocorreu entre os meses de julho e novembro de 2013, quando atores atu- 
antes no âmbito institucional dos projetos foram entrevistados. As entrevistas foram gravadas e orientadas sob um roteiro de perguntas abertas. Os entrevistados foram escolhidos por serem informantes chaves enquanto formuladores, gestores e executores dos projetos. Foram considerados formuladores os funcionários dos órgãos públicos e das organizações envolvidas inicialmente com a elaboração do arranjo dos projetos; como gestores, os funcionários envolvidos diretamente com a gestão administrativa, financeira e técnica dos projetos; e como executores, os responsáveis pela execução prática das ações dos projetos como a mobilização e negociação com os proprietários.

A pesquisa junto a estes atores apoiou-se no trabalho de Cazella et al. (2009), que estudaram como as políticas públicas e os atores institucionais incorporam o referencial da MFA. Para as entrevistas, foram elaboradas questões que abrangiam diferentes dimensões (econômica, social, ambiental e cultural). Tratou-se de considerar os eventuais impactos dos projetos sobre os proprietários rurais, sobre a atividade agrícola e sobre o espaço rural. Paralelamente, as questões diziam respeito aos interesses dos atores que se engajaram nos projetos de PSA-Água, identificando seus cálculos e estratégias em função dos custos e benefícios esperados das ações (Nierdele \& Grisa, 2013). Assim, considerou-se a narrativa dos atores em diferentes tópicos, a fim de identificar em que medida reconheciam, desconsideraram, valorizaram ou desvalorizaram as diferentes dimensões em torno do referencial de MFA.

No ProdutorES de Água, foram realizadas 14 entrevistas junto a representantes do Instituto Estadual de Meio Ambiente e Recursos Hídricos, do Instituto Capixaba de Pesquisa e Extensão Rural, do Instituto de Defesa Agropecuária e Florestal, da Prefeitura Municipal de Alfredo Chaves e da organização não governamental (ONG) Instituto BioAtlântica. No Conservador das Águas, foram entrevistados o coordenador do projeto (em duas ocasiões), o coordenador das atividades de campo e o funcionário da ONG The Nature Coservancy (TNC) que acompanha o desenvolvimento do projeto. No Projeto Piloto, foram entrevistados representantes da Prefeitura Municipal de Joanópolis, da Coordenadoria de Assistência Técnica Integral de Joanópolis, da Casa de Agricultura de Nazaré Paulista, do Comitê PCJ, da TNC (que coordena o projeto) e o técnico da empresa de assessoria que realizou a mobilização local em torno do projeto.

\section{Origens dos projetos de PSA-Água}

\subsection{ProdutorES de Água}

A nível estadual, nosso estudo focalizou o dispositivo PSA capixaba. Os primeiros impulsos para se pensar a formulação de um projeto que incorporasse o mecanismo de PSA começaram em 2005 no âmbito do Instituto Estadual de Meio Ambiente e Recursos Hídricos (IEMA), órgão vinculado à Secretária de Estado de Meio Ambiente e Recursos Hídricos do Espírito Santo (SEAMA). O interesse em formular um projeto deste tipo partiu de funcionários do IEMA/SEAMA sob forte estímulo de um profissional ligado à $\mathrm{ONG}$ chamada Instituto BioAtlântica (Ibio), tendo também, recebido apoio inicial de experts da TNC. Estas duas ONGs se tornariam posteriormente parceiras na execução do projeto ProdutorES de Água. 
Em 2006, teve início a elaboração da proposta do projeto Florestas para a Vida, que abrigava o mecanismo de PSA-Água. Essa proposta foi submetida ao Fundo Global de Meio Ambiente (GEF) por meio do Banco Mundial (BM) visando angariar financiamento. Porém, segundo um dos formuladores do Florestas para a Vida, devido à morosidade do processo de aprovação da proposta junto ao BM e à existência de crescente interesse e pressão direta do governador do estado para implementar o mecanismo de PSA no Espírito Santo, um grupo de trabalho passou a elaborar o desenho do ProdutorES de Água. Assim, conforme o entrevistado, dentro do IEMA/SEAMA foram desenvolvidas duas linhas distintas do mecanismo de PSA-Água. A primeira, sob as orientações do BM, foi baseada explicitamente na teoria econômica, com o objetivo de identificar potenciais consumidores para criar um futuro mercado de serviços ambientais, cuja condução foi mais paulatina. A segunda linha foi direcionada a implementar rapidamente o mecanismo de PSA no estado, cujo pagamento assumiria mais um caráter de subsídio aos proprietários rurais, o que acabou sendo viabilizado em primeiro lugar no ProdutorES.

No decorrer do trabalho para a formulação do ProdutorES de Água, o corpo técnico do IEMA/ SEAMA procurou conhecer experiências de referência na implementação do PSA-Água, tais como a Política Nacional de Pagamento por Serviços Ambientais na Costa Rica e o projeto Conservador das Águas em Extrema/MG. Esta equipe se dedicou também ao estudo aprofundado de aspectos econômicos, ambientais, técnicos e jurídicos em torno do mecanismo de PSA-Água. A Agência Nacional das Águas disponibilizou uma base de conhecimento consolidado através do "Programa Produtor de Água". Conforme um dos formuladores do projeto, o modo de cálculo para determinar o valor do PSA deriva deste programa. Em contrapartida, nenhum estudo socioeconômico prévio foi realizado na área da Bacia do Rio Benevente, primeira localidade onde se implementou o projeto. Os proprietários rurais foram consultados após a elaboração do projeto. Conforme um dos gestores entrevistados: “o proprietário era só beneficiário. Ele não participava em nenhuma cadeia anterior de tomada de decisão.".

Independentemente de dimensões de importância (econômicas, sociais, ambientais e culturais) em torno do público-alvo e de sua motivação em participar de um projeto de PSA, havia dentro do primeiro escalão do governo grande interesse no mecanismo de PSA. Tal fato explica a inscrição do ProdutorES de Água na "carteira de projetos estruturantes para o estado do Espírito Santo", conforme um dos formuladores do projeto. Este arranjo levou, em 2008, à homologação e regulamentação de leis que criaram o Programa de PSA (chamado de ProdutorES de Água) e o Fundo Estadual de Recursos Hídricos (FUNDÁGUA). Desse modo, emerge a primeira iniciativa estadual de PSA-Água com fundo de financiamento próprio no Brasil (Sossai et al., 2012). O FUNDÁGUA é abastecido por 3\% dos royalties do petróleo e pelos royalties da água (compensações pagas pelas grandes hidrelétricas pelo uso da água) ${ }^{2}$.

De fato, o ProdutorES de Água nasce a partir da iniciativa de funcionários do IEMA/SEAMA que se comprometeram a formulá-lo, geri-lo e executá-lo, mas sob influência de atores externos à esfera governamental. Porém, em última análise,

\footnotetext{
${ }^{2}$ Destes recursos, $60 \%$ são destinados ao Programa de PSA e 40\% para atender a outras demandas da Política Estadual de Recursos Hídricos.
} 
foi o forte interesse político que viabilizou a sua existência como política pública, garantindo a sua base legal e o aporte financeiro necessário à sua implementação.

\subsection{Conservador das Águas}

A nível municipal, nosso estudo abordou o projeto de PSA de Extrema/MG. Para seu idealizador, o Conservador das Águas "foi uma evolução". Em 1996, o interesse político de representantes de municípios da região sul de Minas Gerais levou à mobilização de esforços para a construção e execução do projeto "Recuperar e Preservar as Águas dos Mananciais de Consumo e Desenvolvimento do Médio Sapucaí". Esta proposta comum a diversos municípios da região tinha três frentes de ação, a saber: restauração florestal, conservação de solos e saneamento básico no meio rural. Com efeito, estas ações foram os embriões das práticas conservacionistas do projeto Conservador das Águas (Chiodi et al., 2013).

Os recursos para sua execução foram disponibilizados pelo Ministério do Meio Ambiente, pela linha Projetos de Execução Descentralizados, que distribuía recursos do Programa Nacional de Meio Ambiente. Este programa fomentou parcerias entre atores regionais para recuperar áreas de preservação permanente em propriedades rurais.

Desta forma, houve cooperação entre órgãos de diferentes níveis de governo: seis prefeituras municipais, como gestoras do projeto; a Empresa de Assistência Técnica e Extensão Rural de Minas Gerais (EMATER), como executora; e, enquanto apoio, o Instituto Brasileiro do Meio Ambiente e Recursos Naturais Renováveis (IBAMA). Neste período, Extrema não dispunha de um escritório da EMATER, mas destinou um funcionário da prefeitura para acompanhar o projeto que acabou assumindo a coordenação regional dos trabalhos, e tornou-se o idealizador e realizador do Conservador das Águas (Chiodi et al., 2013).

Em 2001, havia uma notável estabilidade política em razão de uma continuidade administrativa ${ }^{3}$ e do conhecimento técnico acumulado para criar um projeto de conservação ambiental em Extrema/ MG. A limitação para tal empreitada estava na disponibilidade de informações detalhadas do quadro socioambiental do meio rural. A execução de outro projeto denominado "Água é Vida - Manejo e Monitoramento em Sub-bacias Hidrográficas" permitiu a contratação de assessoria técnica, a aquisição de imagens de satélite, o cadastramento e georreferenciamento de propriedades rurais e a subdivisão do município em sub-bacias hidrográficas (Pereira, 2013).

A ANA se aproximara da administração municipal em 2002 com intuito difundir o Programa Produtor de Água. Além deste estímulo, a TNC reconheceu no município um campo propício para difundir e apoiar a elaboração e implementação de projetos fundados no mecanismo de PSA-Água. Estes atores institucionais se tornaram parceiros permanentes da prefeitura no decorrer do desenvolvimento do Conservador das Águas.

Ainda, o projeto "Água é Vida" viabilizou previamente negociações com os proprietários vinculados à Associação do Bairro das Posses

\footnotetext{
${ }^{3}$ Em 2012, o grupo político à frente da prefeitura municipal completou oito mandatos na administração pública. Esta constância vem possibilitando a continuidade de certas políticas municipais.
} 
(sub-bacia piloto). Portanto, houve uma abertura de diálogo entre formuladores do dispositivo local de PSA e um grupo de proprietários rurais antes de se implantar o projeto na prática. Segundo o coordenador do projeto, buscou-se saber a opinião do grupo sobre o interesse em aderir a um projeto de remuneração por medidas de proteção de parcelas de suas propriedades e sobre as condições para tal adesão.

Assim, a partir da convergência entre a experiência adquirida e das informações técnicas acumuladas graças aos projetos anteriores, foi proposto o desenho técnico operacional do projeto Conservador das Águas com uma certa adaptação do mecanismo PSA à realidade local. Com o respaldo político, a lei de sua criação foi aprovada em 2005, viabilizando aporte financeiro e alocando-o no âmbito do Departamento de Serviços Urbanos e Meio Ambiente.

\subsection{Projeto Piloto no PCJ}

O Projeto Piloto Produtor de Água no Comitê das Bacias Hidrográficas dos Rios Piracicaba, Capivari e Jundiaí (PCJ) é concebido efetivamente dentro da Câmara Técnica de Uso e Conservação da Água no Meio Rural. Trata-se de uma implementação pioneira do Programa Produtor de Água da ANA. Embora apresente certa flexibilidade, o Projeto Piloto segue os conceitos, o modelo de operação, a estrutura, o arranjo organizacional e a forma de pagamento propostos pelo referido programa (ANA, 2013).

A existência do Projeto Piloto pode ser creditada à confluência de interesses institucionais mobilizados por funcionários da TNC, da ANA e da Secretaria Estadual de Meio Ambiente de São Paulo SMA/SP. Posteriormente, tais instituições assumiriam o compromisso de sua gestão e execução, sendo a TNC a tomadora do recurso financeiro junto ao Comitê PCJ. Além destes atores, houve igualmente o envolvimento de representantes do próprio Comitê PCJ, da Coordenadoria de Assistência Técnica Integral (CATI/SP) e das Prefeituras de Joanópolis, de Nazaré Paulista e de Extrema.

No campo da política interna do Comitê PCJ, os funcionários destas instituições foram capazes de abrir espaço para a implantação do projeto, quando uma deliberação conjunta foi aprovada, em 2006, o que permitiu criar o Projeto Piloto como uma ação de curto prazo do Plano das Bacias Hidrográficas dos Rios Piracicaba, Capivari e Jundiaí. Com tal procedimento, o pagamento (PSA) foi financiado com recursos da cobrança pelo uso da água captados nas bacias PCJ. O Projeto Piloto foi apresentado como de interesse geral do Comitê PCJ pelo seu enfoque na gestão dos recursos hídricos.

Em 2009, uma chamada para a adesão ao projeto de proprietários rurais nas sub-bacias hidrográficas do Cancã e do Moinho teve início. Nestas sub-bacias, já vinha sendo desenvolvido o Programa de Recuperação de Matas Ciliares (PRMC) da SMA/SP, financiado pelo Banco Mundial, que visou especificamente recuperar áreas de preservação permanente (APP) hídricas. Segundo um dos gestores do Projeto Piloto, um dos objetivos iniciais do projeto seria o de integrar ações públicas. Tratava-se de ampliar o impacto do PRMC (que financia práticas de restauração florestal) e remunerar os proprietários engajados por seus esforços conservacionistas. O Projeto Piloto ainda se integraria ao Programa Estadual de Microbacias Hidrográficas (Microbacias I) da Secretária Estadual de Agri- 
cultura e Abastecimento SAA-CATI/SP, também financiado pelo Banco Mundial, que notadamente fomenta práticas de conservação de solos.

Desse modo, informações geradas pelo PRMC sobre o contexto social e ambiental dos bairros do Cancã e do Moinho foram úteis para a concepção do mecanismo de PSA-Água, que contou ainda com um diagnóstico socioeconômico e um levantamento da percepção dos proprietários rurais sobre o pagamento por serviços ambientais. Esta última ação visou também despertar o interesse pelo projeto.

Tal empenho não impediu o surgimento de dificuldades para a operacionalizar o Projeto Piloto. Devido a diversos obstáculos, o seu cronograma inicial sofreu atrasos e, quando foi possível colocá-lo em prática, em 2011, os programas PRMC e Microbacias I estavam sendo finalizados. De fato, houve pouca adesão por parte dos proprietários rurais, além da grande dificuldade em organizar uma agenda de trabalho comum entre os técnicos das diferentes instituições que realizavam inicialmente a mobilização em campo dos eventuais interessados e elaboravam os projetos executivos para as propriedades.

Estas dificuldades, segundo um dos coordenadores do projeto, foram determinantes para pensar e operar novas estratégias. A principal transformação ocorreu na estrutura de funcionamento do projeto, após o estabelecimento de novas parcerias. Estas entraram com aporte financeiro para assegurar as metas de restauração florestal e de conservação do solo, além de permitir ampliar a mobilização em campo junto aos proprietários. Desta forma, a escolha foi por terceirizar essas ações. Uma empresa de assessoria técnica foi contratada para cuidar da mobilização, negociação e elaboração de projetos executivos enquanto outra tornou-se responsável pelas práticas de restauração florestal (plantio e manutenção de mudas de árvores nativas).

Assim, o Projeto Piloto é o resultado da convergência de atores interessados na difusão do mecanismo de PSA-Água, tendo inscrito este último no quadro de ações prioritárias da política de gestão dos recursos hídricos. Desta maneira, foi viabilizado aporte técnico, pelo programa da ANA, e financeiro, via Comitê PCJ.

\section{Os atores institucionais e os seus papeis}

A princípio, os atores pesquisados foram identificados a partir do envolvimento com os processos de formulação, gestão e execução dos projetos de PSA-Água. Por esta razão, foram denominados de formuladores, gestores e executores. Mas após as entrevistas, foi possível identificar, de modo mais específico e analítico, três categorias de atores institucionais, definidas como: i) atores técnicos (funcionários dos órgãos públicos e das organizações proponentes dos projetos); ii) atores políticos (representantes da classe política interessados nos projetos); e iii) atores parceiros (representantes de instituições que colaboraram com os projetos).

Convém neste ponto ressaltar que os atores técnicos e os atores políticos foram centrais para a formulação dos projetos. Os atores técnicos que se empenharam na formulação do desenho do ProdutorES de Água foram funcionários do quadro técnico do IEMA/SEAMA, com maior relevância para aqueles que ocupavam cargos mais altos na hierarquia do órgão público. Do mesmo modo, no Conservador das Águas, o destaque pode ser atribuído ao secretário de meio ambiente do município que também era um funcionário permanente do quadro 
da prefeitura. No Projeto Piloto, os funcionários de perfil técnico (alocados em cargos de coordenação e de direção) da TNC, da SMA-SP e da ANA envolvidos no projeto foram os atores responsáveis por imprimir um piloto do Programa Produtor de Água. Os atores políticos também contribuíram para a formulação dos desenhos dos projetos, mas, principalmente, para sua aprovação e viabilidade financeira. Este grupo foi identificado enquanto representantes do poder Executivo e Legislativo do estado do Espírito Santo (governador, secretários de estado e deputados estaduais) e do município de Extrema/MG (prefeito, secretários municipais e vereadores), além dos tomadores de decisão dentro do Comitê PCJ (secretário executivo do comitê e coordenadores de câmaras técnicas).

Os gestores e os executores também foram identificados como atores técnicos, pois são funcionários ocupantes de cargos de nível operacional dentro da estrutura organizacional das instituições (administradores, agrônomos, engenheiros florestais, biólogos, técnicos ambientais, técnicos agrícolas, etc.). Vale dizer que foi comum identificar formuladores que assumiram o papel de gestores dos projetos, como ocorreu no Conservador das Águas e no ProdutorES de Água, tendo sido responsáveis por gerir as rotinas administrativas, seguir as regras jurídicas, operar ou supervisionar o funcionamento do esquema financeiro e acompanhar as operações na escala técnica dos projetos. Os executores foram os responsáveis pela materialização em campo dos projetos, sensibilizando e mobilizando proprietários rurais, negociando e dialogando com eles, elaborando os projetos executivos das propriedades e implementando, acompanhando e mantendo as práticas conservacionistas em questão.
A partir da identificação desse arranjo de atores, foi possível considerar que aqueles técnicos possuíam a capacidade de formular, gerir e executar os projetos, mas foram os atores políticos que tiveram o poder de decisão sobre a sua aceitação e sobre sua viabilidade. Com efeito, a aprovação de regulamentações legais que garantiram o aporte financeiro necessário foi negociada por este grupo. Assim, foi a conjunção da capacidade técnica e do poder de decisão política que permitiram a consistência técnica e a existência legal dos projetos.

Os atores técnicos, portanto, conformaram o núcleo duro dos projetos, mas eles estiveram envoltos por um conjunto de atores parceiros. Tais atores influenciaram efetivamente os processos de formulação, gestão e execução dos três projetos em questão. Além disso, injetaram nos projetos motivações, conhecimentos, informações, e recursos humanos e financeiros que permitiram a realização, o aperfeiçoamento e a continuidade dos projetos. No ProdutorES de Água, destaca-se a atuação de um técnico do Ibio que contribuiu com a formulação, gestão e execução do projeto e de técnicos da TNC que influenciaram e apoiaram sua consolidação. No Conservador das Águas, segundo o seu idealizador, a proposta já estava pronta. Os parceiros foram procurados para sua realização e para suprir e fortalecer componentes relevantes do seu escopo. Aqui, o destaque recai sobre o papel da TNC como uma das primeiras e permanentes instituições parceiras. O Projeto Piloto possui uma gestão mais compartilhada, agregando parceiros ao longo de sua trajetória de forma a complementar e cumprir metas, como a World Wildlife Fund (WWF-Brasil), a Associação Mata Ciliar e a Iniciativa Verde. Desse modo, alguns atores parceiros foram mais determinantes para a 
existência dos projetos e outros se integraram ao longo do tempo de modo mais pontual.

Considerando a relevância das organizações não-governamentais ambientalistas para a existência dos projetos de PSA-Água, seu papel merece ser mais discutido. Trata-se de um papel desempenhado a nível internacional, como revelam Hrabanski \& Valette (2012) sobre a atuação de ONGs ambientalistas na rápida difusão da noção de serviços ambientais na Europa. A influência das ONGs transnacionais - dentre as quais a maior em termos de recursos financeiros administrados é a TNC - sobre políticas ambientais e instituições governamentais em países do Terceiro Mundo começou na década de 1980. Segundo Diegues (2008), o poder de influência das grandes ONGs deriva dos investimentos financeiros que elas realizam em programas ambientais nestes países, o que gera, por consequência, o estabelecimento de conexões dentro dos órgãos de governo, permitindo que as ONGs possam emprestar sua expertise ambiental aos governos nacionais. Um dos resultados marcantes deste poder de influência foi a expansão das áreas protegidas no Brasil nas últimas três décadas.

Voltando para o nosso enfoque, com o encontrado, podemos creditar, em grande parte, a existência do mecanismo de PSA-Água a este poder de influência das ONGs ambientalistas, que assumiram o papel de mediadores do referencial de serviços ambientais junto a diferentes órgãos públicos. Aderindo à Pierre Muller, os mediadores são os atores que se encontram de modo cada vez mais evidente em espaços públicos distintos e são os responsáveis pelo processo de "tradução" que deve existir entre os dispositivos cognitivos e valorativos (Nierdele \& Grisa, 2013). Ou seja, mediadores traduzem o referencial de serviços ambientais no nível de políticas públicas.

No entanto, existiu uma esfera mais ampla de atores parceiros que extrapola o mundo das ONGs, oriundos dos diferentes setores da sociedade - Estado, iniciativa privada e sociedade civil. Os recursos aportados por eles também foram distintos: a) técnico (sobretudo para treinamentos); b) financeiro (assegurando ações, pagamentos por serviços ecossistêmicos e subsídios); c) conhecimento (informações e educação ambiental); d) material (equipamentos, mudas e mourões); e) operacional (sensibilização e mobilização local).

De modo geral, identificou-se que uma das caraterísticas comuns aos projetos de PSA-Água estudados é a maneira de agir dos representantes do Estado em relação aos atores parceiros. Nos casos do ProdutorES de Água e do Conservador das Águas, esta ação permitiu que o Estado fosse permeável aos atores com interesses privados $(\mathrm{ON}-$ Gs e empresas privadas), fenômeno explicado por Marques (2003) pela existência de redes de relações estreitas entre atores públicos e privados. No caso do Projeto Piloto, conforme Massadier (2011), o Estado favoreceu a constituição de uma arena de negociação e de formulação da política pública por intermédio de seus funcionários. No entanto, em nenhuma entrevista realizada com os formuladores e gestores dos projetos, os proprietários rurais foram identificados como atores parceiros. Tal desconsideração demonstra que os projetos estabeleceram múltiplas relações entre Estado e interesses privados, porém sem incluir os agricultores como agentes ativos do processo.

As instituições são "construções sociais da realidade” (Berger \& Luckmam, 2012), o que leva a pensar que as inclinações dos atores implicados em 
determinada construção institucional são decisivas para sua orientação. Nesta ótica, os atores técnicos e parceiros, por estarem vinculados a instituições construídas para promover a proteção, a conservação e a recuperação ambiental, concebem estes fins como prioritários, quando não exclusivos. Como afirmou o coordenador do Conservador das Águas sobre o projeto: “o foco principal é aumentar a cobertura florestal do município e é fazer a restauração". No caso do Espírito Santo, o IEMA é o órgão responsável por aplicar a legislação ambiental, ou seja, ele cumpre principalmente o papel de assegurar a proteção ambiental. Por fim, a TNC é uma ONG norte-americana conservacionista amplamente conhecida por seu modelo focado na conservação (Diegues, 2008).

Desse modo, é pertinente interpretar que as três experiências foram limitadas para o reconhecimento da multifuncionalidade da agricultura e do espaço rural, ainda mais que a participação dos proprietários rurais nas diferentes etapas do processo de tomada de decisão, em particular dos agricultores familiares, foi negligenciada.

\section{Os interesses dos atores para a ação}

O ProdutorES de Água na Bacia do Rio Benevente, expressão veiculada na própria lei que cria o projeto, teve "como objetivo recompensar financeiramente o proprietário rural, em função do valor econômico dos serviços ambientais prestados por sua área destinada para a cobertura florestal" (Espírito Santo, 2008). Em publicação científica, os formuladores deste dispositivo afirmam: "este projeto, por meio de PSAs, reconhece os proprietários rurais que conservam florestas nas margens de rios, córregos e nascentes, contribuindo para o combate à erosão, ao assoreamento e a infiltração de água no solo" (Sossai et al., 2012, p. 9). Assim, trata-se de reconhecer os proprietários rurais - que na Bacia do Rio Benevente são em sua maioria agricultores familiares - como agentes da conservação ambiental.

No entanto, examinando mais de perto o processo, foi possível considerar que a efetivação do reconhecimento dos proprietários rurais não foi central para a formulação do ProdutorES de Água. A partir das diversas entrevistas junto aos formuladores e gestores do projeto, tornou-se claro que os interesses preponderantes foram de duas ordens: i) o interesse político de implementar de modo pioneiro o mecanismo de PSA-Água no estado do Espírito Santo, demarcando a preocupação agroambiental do grupo governante e ii) o interesse dos atores técnicos em desenvolver respostas pertinentes diante do desafio de operar uma política pública inovadora.

$\mathrm{O}$ interesse político se atrelou à estratégia de dar maior visibilidade a ação governamental. Conforme um dos formuladores, "o projeto Produtores de Água nasceu com uma força política tão interessante porque é um assunto palatável para falar politicamente". Outro interlocutor nos confiou que "quando o governador da época, Hartung, viu que tinha uma política pública se desenvolvendo, mas também viu uma boa credencial política, era algo que mostrava uma política do governo no meio rural". Além de visibilidade para a ação do governo, a lógica subjacente do interesse político no mecanismo de PSA-Água, antes do reconhecimento do papel ambiental do proprietário rural, consistia em ativar um mercado para os serviços ambientais. De fato, a água da Bacia do Rio Benevente já estava sendo utilizada por uma grande siderúrgica e, na época, havia a expectativa de instalação de 
outra. Tratava-se de um cenário propício ao estabelecimento de uma relação entre fornecedores e consumidores de serviços ambientais hidrológicos. Segundo um dos entrevistados, "a primeira bacia a ser escolhida .... [teve] o dedo do governador". Como descreveu:

Primeiro que o Benevente tem muita água ainda. Tem muita cobertura florestal. Era um lugar que a gente sabia que ia ter agricultores para serem reconhecidos, remunerados. Mas o governador achava que essa história do dinheiro dos royalties tinha que ser uma coisa temporária. Não podia pensar em sustentar esse projeto o tempo inteiro. Até porque agora está acabando os royalties. Tinha todo um movimento na região para criar a CSU (Companhia Siderúrgica de Ubú), uma coisa enorme. Tem a Samarco-Mineração... Ele queria já garantir essa coisa do mercado. Que esses caras iam ter que pagar. Não é pagar pela água dele, mas indiretamente pela água que eles estavam tendo que usar para os processos industriais do Benevente. Quem estava garantindo aquela disponibilidade hídrica ali eram esses produtores que deixaram mata e tal. Ele realmente visou que nessa região teria grandes empreendimentos, que teriam condição de dar continuidade e bancar esses produtores (Formulador do ProdutorES de Água, 2013).

Por outro lado, o interesse dos atores técnicos foi despertado pelo próprio desafio de implementar o mecanismo de PSA-Água, apesar da pressão política. Como um dos gestores e executores do projeto afirmou, "o objetivo central do projeto Produtores de Água era iniciar o serviço de pagamento por serviço ambiental no estado do Espírito Santo. Foi de criação, de arcabouço legal, de fluxo, de procedimentos, de processos, de técnica para tratar esse assunto". Reconhecer proprietários rurais foi uma meta a ser atingida, mas não o objetivo a ser alcançado. Como o gestor afirmou, "reconhecer duzentas propriedades até o final do projeto [...] é uma meta mínima que a gente bateu, mas não era o foco". Essas declarações, reproduzidas por outros entrevistados, permitem entender melhor o desenho simplificado do projeto, que pagou proprietários com florestas conservadas e não exigiu nenhuma ação ambiental adicional.

Neste caso, mesmo que a transferência monetária enquanto reconhecimento aos agricultores que conservaram florestas estivesse em segundo plano na lógica desta iniciativa, ela foi usada como uma justificativa pública. Com efeito, a motivação efetiva que levou os atores políticos e técnicos a se empenharem na consolidação do projeto foi sobretudo seu potencial de visibilidade política, a criação de um novo tipo de mercado e o aprendizado desafiador desejado pelos gestores públicos.

Quanto ao projeto Conservador das Águas, apoiar proprietários rurais é um dos intuitos do projeto, uma vez que no próprio título da lei "autoriza o executivo a prestar apoio financeiro aos proprietários rurais" (Extrema, 2005). A concepção de "apoio" pode ser entendida como a forma de reconhecer e valorizar a conservação ambiental efetuada pelos agricultores. De todo modo, tal apoio visava o cumprimento de uma única função da propriedade rural, como pode ser interpretado a partir da manifestação de um formulador e gestor do projeto:

O foco do projeto foi fazer a restauração florestal, esse foi o foco. E nós utilizamos o pagamento como um instrumento pra gente conseguir a restauração. Então, a ideia era restaurar as Áreas de Preservação Permanente em áreas privadas e o projeto ele veio para ser um instrumento pra gente conseguir fazer isso. Um apoio financeiro para os agricultores para que eles pudessem abrir as porteiras pra gente poder 
fazer a restauração (Formulador e gestor do Conservador das Águas, 2013).

Claramente, a transferência monetária foi pensada principalmente para alcançar a restauração florestal. Em outra passagem, o mesmo entrevistado indicava "a gente pensou muito mais nas propriedades e que o pagamento seria uma forma da gente poder ter o agricultor como nosso apoio, apoiar o projeto da restauração sabendo que aumentaria sua renda, que ele teria uma renda por conta do projeto". Esse depoimento revela que a concepção de apoio centrada na restauração florestal deixa pouca margem para considerar todos os papéis que os agricultores podem desempenhar na sociedade.

De todo modo, o pagamento foi concebido como o canal de diálogo e de convencimento em favor do projeto para a adesão dos proprietários rurais com vistas a efetividade prática do objetivo de restauração florestal. Em outro momento de nossa entrevista, o referido entrevistado declarou:

Não, a renda seria importante para o convencimento do agricultor aderir ao projeto, abrir sua porteira pra gente poder ir lá fazer a restauração. Acho que esse é o caminho, as pessoas que estão no projeto estão no projeto porque estão recebendo, vamos dizer, mais de $90 \%$ das propriedades que estão no projeto estão por conta disso. Se não tivesse pagamento não teria restauração (Formulador e gestor do Conservador das Águas, 2013).

A concepção do projeto parte do entendimento de que os agricultores agem sobretudo para alcançar fins monetários. Assim, para promover a restauração florestal nas propriedades somente o pagamento seria efetivamente eficiente. No entanto, é possível considerar as limitações desta concepção, já que o entrevistado afirmou que, com base na lei ambiental, foi exercida pressão para a adesão de alguns dos proprietários mais relutantes, revelando a insuficiência de uma abordagem economicista.

Passando para o caso do Projeto Piloto, os conceitos difundidos pelo Programa Produtor de Água da ANA constituem seu fundamento, como mencionado acima. Apesar de adaptações locais, o Projeto Piloto assume que a transferência monetária via PSA-Água configura-se em "incentivos econômicos" para melhorar e manter a qualidade ambiental (ANA, 2013).

No entanto, o Projeto Piloto está vinculado a um comitê de bacia hidrográfica, o que implica em existência relacionada diretamente à sua contribuição para a gestão dos recursos hídricos. Como explicou um dos gestores entrevistado, "a lógica do Projeto Piloto foi de colocar em prática o princípio do provedor-recebedor, por isso que o recurso é da cobrança federal do uso da água". Ademais esclarece que "no termo de referência é muito claro, é testar o modelo de PSA", pois "no estado de São Paulo não existia nada e nós estamos testando um modelo".

A partir destes elementos, é nítido que, mesmo existindo uma transferência monetária via PSA-Água enquanto dispositivo de incentivo econômico aos proprietários rurais, o Projeto Piloto incorporou outros interesses. Estes últimos se associam à implementação do PSA-Água como um mecanismo inovador para a gestão dos recursos hídricos. Portanto, o empenho para materializar o mecanismo de PSA-Água via Projeto Piloto esteve assentado no "aprender-fazendo", ou seja, implementar o projeto e acumular conhecimento sobre o processo. $\mathrm{O}$ aprendizado resulta em expertise ambiental. $\mathrm{O}$ expert ou especialista é aquele que adquiriu um 
profundo conhecimento em um campo particular (Kalaora, 1999). Conforme Carneiro (2006), esse conhecimento pode ser detido por um profissional ou por uma instituição, cujo domínio técnico é socialmente reconhecido e validado. É a expertise ambiental que gerará visibilidade institucional e futuras possibilidades para as instituições envolvidas. Diegues (2008) afirmou que o conhecimento técnico-científico e a experiência ambiental em mãos das grandes ONGs ambientalistas se tornam poderes de influência sobre governos de países como o Brasil, no que tange questões e decisões sobre políticas ambientais. Logo, a expertise ambiental resulta em poder. Talvez esteja nesse empoderamento um dos interesses implícitos de diversas ONGs, o que não deixa de favorecer a consolidação de um incentivo econômico como um novo princípio para a gestão dos recursos hídricos. Vale dizer que os principais atores são as ONGs ambientalistas, nacionais e internacionais, que vêm se mobilizando para pressionar o governo brasileiro a aprovar a legislação referente à Política Nacional de PSA, que tramita no Congresso Nacional desde 2007.

Assim, o interesse em reconhecer o agricultor como um ator social que desempenha várias funções na sociedade - tendo a peculiaridade de associar sua profissão com um modo de vida, rompendo com a percepção do agricultor movido exclusivamente por uma racionalidade econômica (Carneiro \& Maluf, 2003 ) - esteve ausente das motivações que levaram os formuladores e os gestores a se empenharem na implementação dos projetos. Pelo contrário, a transferência monetária via PSA-Água reforçou a concepção de que a racionalidade econômica é a base exclusiva para se inter-relacionar com a população rural, o que seria o modo mais eficiente de se alcançar a conservação ambiental. Assim, outras dimensões importantes foram desconsideradas. O discurso de um gestor do ProdutorES de Água ilustra bem esta conclusão:

É por isso que era assim, pelo dinheiro. Não tinha aquela questão de entendimento, talvez se ele fizesse parte do processo... O proprietário não fez parte das discussões, da construção do projeto, ele fez parte lá na mobilização já. O proprietário era um beneficiário do projeto, não era um ator participativo dele." (Gestor do ProdutorES de Água, 2013).

Ao longo das entrevistas realizadas, foram raros os discursos que deixaram transparecer a preocupação em considerar o proprietário rural, seja ele agricultor familiar ou não, como um ator importante para o processo de formulação, gestão e execução dos projetos. De fato, estes projetos de PSA-Água se alimentaram de um reducionismo econômico, conforme apontam Kosoy \& Corbera (2010), uma vez que desconsideraram a complexidade dos sistemas sociais, induziram ao esquecimento de outros valores sociais que emergem das relações entre sociedade-natureza, priorizando somente o valor econômico.

\section{Resultados ambientais e institucionais}

Em Alfredo Chaves/ES, o projeto ProdutorES de Água permitiu a assinatura de 138 contratos, a um custo médio (PSA) de R\$ 141,77 por hectare ao ano. Os contratos cobriam três anos e representaram o compromisso dos proprietários rurais com a conservação de $1.688,82$ hectares de cobertura florestal. O serviço ambiental foi prestado pelos proprietários, uma vez que praticamente nenhum contrato foi descumprido. Não desconsiderando 
esse resultado positivo, o projeto não foi efetivo para promover ações adicionais de recuperação florestal. Esse resultado foi reconhecido pelos gestores do projeto quando escreveram que o ProdutorES de Água por beneficiar somente florestas já existentes teve "pouco efeito" em relação ao aumento da cobertura florestal no estado do Espírito Santo (Sossai et al., 2012, p. 9). Entretanto, apesar do "pouco efeito" em termos de ganhos ambientais, os resultados e os desdobramentos institucionais foram significativamente efetivos.

O governo do Espírito Santo, ao criar o Programa de PSA e garantir seu financiamento com o FUNDÁGUA "carimbou" um montante expressivo de recursos financeiros para a pasta de recursos hídricos dentro do IEMA/SEAMA. Segundo um dos gestores do projeto, entre 2008 e 2012, o fundo captou $\mathrm{R} \$ 33.667 .614,51$ para serem aplicados na conservação de recursos hídricos e de florestas. Mesmo que os recursos não tenham sido empregados para a expansão da infraestrutura e dos recursos humanos do órgão público, a realização do ProdutorES de Água permitiu mobilizar um grupo de funcionários, estruturas físicas e equipamentos para operar o PSA-Água dentro do IEMA. Conforme um dos formuladores do projeto, esse resultado foi significativo, visto que o órgão historicamente teve como prioridade o licenciamento ambiental. Efetivamente, a criação do FUNDÁGUA, enquanto meio de financiar dispositivos como o PSA-Água, significou poder de decisão e de implementação de ações mais voltadas à conservação ambiental dentro do órgão público.

Mais expressivo, no entanto, foram os desdobramentos derivados da continuidade dos trabalhos do grupo que mobilizou o mecanismo de PSA. O IEMA contratou, a um custo de 3,6 milhões de re- ais, um serviço de imageamento e de mapeamento da ocupação do solo do estado do Espírito Santo, além da elaboração e implementação de um modelo (com uso de software específico) para acompanhar a dinâmica da cobertura florestal (Sossai et al., 2012). Tal geração de informações acarretará em melhores condições para o planejamento e gestão ambiental no estado. Por outro lado, recursos na ordem de 38 milhões de reais foram aprovados junto ao Banco Mundial para as ações do órgão, dentre as quais ampliar o uso do mecanismo de PSA, via um novo projeto.

Enquanto os ganhos do ProdutorES de Água não foram eficazes em termos de adicionalidade ambiental, o projeto Conservador das Águas obteve resultados ambientais efetivos. Segundo Pereira (2013), as práticas de restauração florestal, de conservação dos solos e de saneamento ambiental foram realizadas em praticamente todas as propriedades elegíveis das sub-bacias das Posses e do Salto. Entre 2007 e 2013, o projeto alcançou 161 contratos assinados, atingindo 5.619 hectares em propriedades privadas com alguma ação de conservação. Foram 187.529 metros de cercas construídas, instalados 30 biodigestores e 50 caixas d'água, plantadas 504.153 mudas de espécies nativas, construídas 1.000 bacias de contenção de enxurrada (barraginhas) e terraços em 100 hectares de áreas ocupadas por pastagens (Extrema, 2015).

Se o projeto Conservador das Águas promoveu resultados ambientais efetivos, em termos institucionais, os seus resultados foram mais surpreendentes. Um verdadeiro empreendimento de sucesso, é o que considera o idealizador do projeto:

É nós criamos uma estrutura para o projeto. Nós começamos bem pequeno e depois assim que o projeto 
foi evoluindo nós fomos melhorando o nosso quadro pessoal, nossa estrutura física, nossos equipamentos, veículos. Nós fomos crescendo à medida que o projeto foi crescendo (Formulador e gestor do Conservador das Águas, 2013).

De fato, a equipe de três funcionários aumentou para trinta, em 2013. A ampliação da estrutura física da sede da Secretária Municipal de Serviços Urbanos e Meio Ambiente, a aquisição de veículos e de equipamentos foram possíveis por meio de recursos de parceiros, como nos revelou o entrevistado. Parte do dinheiro arrecadado graças à iniciativa vem sendo usado para a aquisição de terras pela prefeitura. Até 2013, foram 90 hectares comprados de particulares para fins de conservação ambiental das áreas mais altas do município (Extrema, 2015).

Em 2007, foram gastos menos de R \$ 100.000,00 na execução do projeto. Para 2014, a previsão era de $\mathrm{R} \$ 2.200 .000,00$. Até 2010, R\$ 5.089.565,00 tinham sido captados para o projeto, sendo que somente $\mathrm{R} \$$ 1.000.000,00 veio da Prefeitura Municipal (Pereira, 2013). Com este arranjo, a Prefeitura Municipal teve a capacidade de injetar mais de $\mathrm{R} \$ 2.000 .000,00$ no comércio local por meio da compra de insumos e máquinas, contratação de pessoal, e manutenção de equipamentos (Pereira, 2013). Até 2013, a partir da entrevista com o coordenador do projeto, foi possível estimar que foram movimentados cerca de $\mathrm{R} \$ 11.500 .000,00$ com o projeto. No entanto, para o pagamento direto aos proprietários, o montante não chegou a $20 \%$ do custo total do dispositivo ( $\mathrm{R} \$$ 2.298.102,00).

O Conservador das Águas pôde expandir suas ações para o campo da educação: além de levar atividades pedagógicas às escolas do município, oferece cursos pagos sobre o mecanismo de PSA-
-Água com o intuito de repassar sua expertise de aplicação do mecanismo. No município, está sendo criado o Parque Natural Municipal, que abrigará um centro de referência (a um custo inicial de R\$ $823.176,80$ ), onde futuramente serão ministrados os cursos sobre o PSA-Água. Ainda, o município de Extrema/MG ganhou visibilidade nacional graças ao Conservador das Águas, que foi tema especial em dois episódios do Programa Globo Rural e angariou prêmios nacionais e internacionais. Desta maneira, vem atraindo o interesse de grandes empresas como a Panasonic e a Bauducco dentro iniciativa chamada “compromisso das águas", visando ampliar esforços para a preservação dos mananciais do município pelo financiamento de ações do projeto (Extrema, 2015).

Quanto ao terceiro caso estudado, o Projeto Piloto permitiu a assinatura de 41 contratos com proprietários rurais por três anos, referindo-se à: a) conservação de 317,7 hectares de fragmentos florestais; b) restauração florestal de 58,97 hectares em APP hídrica; c) manutenção de 10,48 hectares de APP estabelecidas pelo Programa de Recuperação de Mata Ciliar e d) construção de 267 barraginhas de contenção de enxurradas, equivalente a 98 hectares de práticas de conservação do solo. Mesmo que se possa avaliar como positivos os resultados alcançados na medida em que se trata de um projeto piloto, convém notar que os resultados ambientais ficaram aquém dos resultados esperados e atingiram parcela reduzida das sub-bacias hidrográficas. O projeto aprovado pelo Comitê PCJ deveria atingir 540 hectares de florestas a conservar; 208 hectares de restauração e 530 hectares de práticas de conservação do solo (Padovezi et al., 2013).

Como foi possível constatar, o resultado ambiental mais amplo foi aquele de manter a cober- 
tura florestal existente. Na sub-bacia do Ribeirão Moinho, havia um passivo ambiental em APP hídrica de 199 hectares (Padovezi et al., 2013). O Projeto Piloto financiou a restauração florestal em 4 hectares, que equivalem a $2 \%$ da área potencial de recuperação. Na sub-bacia do Cancã, o passivo era de 194 hectares (Padovezi et al., 2013). As ações de restauração alcançaram 66 hectares (36\% do passivo ambiental). Ademais, deve-se insistir sobre a restrita abrangência e dispersão das ações dentro das sub-bacias hidrográficas, o que minimiza a capacidade de geração de serviços ambientais em escala de bacia hidrográfica.

Vale ressaltar que o custo total da restauração florestal chega a $\mathrm{R} \$ 29.100,00$ por hectare para realizar o plantio total, o cercamento e a manutenção por quatro anos. $\mathrm{O}$ valor médio pago aos proprietários que aderiram ao componente de restauração florestal chegou a R\$183,61 por hectare ao ano. Desse modo, o custo com o PSA por hectare se torna praticamente insignificante diante do custo desse método de restauração florestal no orçamento do projeto.

Neste caso, os ganhos institucionais não se associam ao cumprimento das metas estabelecidas, mas se tornaram importantes, assim mesmo, para os atores envolvidos. Apesar do Projeto Piloto ter mobilizado uma quantia razoável de recursos financeiros (o valor divulgado, subestimado chegou a R\$ 932.250,004), tal montante não se transformou em infraestrutura, equipamentos, recursos humanos ou novos investimentos para as instituições implicadas. O grande ganho para os envolvidos está na confluên- cia entre a visibilidade institucional por se inscrever como um projeto pioneiro de PSA-Água em uma das bacias hidrográficas mais críticas do Brasil e a expertise ambiental acumulada no processo de gestão e execução de um mecanismo inovador e promissor. Com efeito, é a visibilidade dos atores envolvidos que lhes atribui a qualidade de experts, o que lhes confere poder político para influenciar em novas políticas públicas de PSA, permitindo gerar novas oportunidades profissionais. Hrabanski \& Valette (2012) mostram esse tipo de fenômeno com a emergência da noção de serviços ambientais e do PSA na França.

A propósito, Carneiro (2006) examina a importância que o saber acumulado por um conjunto restrito de profissionais e instituições (experts) teve na consolidação da certificação florestal na Amazônia brasileira. $\mathrm{O}$ autor identificou que diferentes iniciativas associadas ao mercado de exploração florestal certificada (elaboração dos padrões de certificação, difusão da tecnologia da exploração florestal de baixo impacto, formação do grupo de compradores de madeira certificada) exigiu investimentos de ONGs que mobilizaram a defesa da certificação florestal como o contraponto ao processo de destruição florestal. Tais investimentos envolveram diferentes frentes de ação (marketing, lobby, pressão política, pesquisa), competências profissionais variadas (ecologia, economia, florestal) e um volume expressivo de recursos financeiros. Para ter acesso a esses recursos, as ONGs desenvolveram competências específicas sobre o conhecimento, a difusão de uma tecnologia florestal (a exploração de

\footnotetext{
${ }^{4}$ Como os recursos provieram de diferentes instituições e são diferenciados entre recurso líquido e contrapartida, os entrevistados não puderam apresentar os valores exatos. Sabe-se que dos Comitês PCJ vieram R\$395.250,00, em contrapartida da TNC, R\$137.000,00 (Padovezi et al., 2013). A WWF com recursos da Fundação Banco do Brasil contribuiu com R\$ 400.000,00. A Associação Mata Ciliar repassou recursos para a construção de barraginhas e a Iniciativa Verde para a restauração florestal.
} 
baixo impacto) e o comércio de madeiras tropicais, a partir das quais se posicionam com vantagens no mercado em expansão em torno do desenvolvimento sustentável (Carneiro, 2006).

Nesse sentido, convém destacar que o Projeto Piloto teve um componente considerável de publicidade, apesar dos resultados ambientais pouco efetivos. O projeto foi amplamente divulgado no Comitê PCJ, que reúne representantes do governo do estado de São Paulo e de Minas Gerais, de 75 municípios, do setor privado e da sociedade civil organizada. A mídia televisiva regional divulgou a execução do projeto. Além, é claro, dos folders, cartazes, placas, sites e palestras de divulgação do projeto com os logotipos das instituições envolvidas. A publicidade dada ao projeto se torna positiva aos órgãos públicos por expor uma ação desejável do Estado à sociedade, mas ainda é mais imprescindível às ONGs ambientalistas, que estão cada vez mais competindo por espaços de atuação em temas ambientais, o que lhes reverterá em recursos financeiros e crescimento institucional (Diegues, 2008).

Com efeito, os ganhos de visibilidade e de expertise ambiental foram resultados institucionais centrais em todos os casos estudados. Nossa interpretação aqui focaliza a capacidade de arrecadação das grandes ONGs ambientalistas, tanto de grandes corporações privadas como de agências de financiamento bi e multilaterais ou de governos locais, que se assenta em grande medida na sua credibilidade profissional e expertise ambiental alcançadas a partir da busca de seus objetivos de conservar a natureza (Diegues, 2008). Os nossos resultados indicam que estes requisitos valem também para órgãos públicos, como demonstra o caso da Prefeitura Municipal de Extrema/MG, via Conservador das Águas, que, devido ao sucesso do projeto, vem atraindo o interesse e os recursos financeiros do setor privado, de ONGs e do setor público. A visibilidade da expertise ambiental das grandes ONGs ambientalistas, nacionais e locais, as legitimam como o que Almeida Jr. \& Gomes (2012) designaram de agentes testemunhas no campo da mídia socioambiental. Devido ao crescente interesse de empresas privadas em melhorar sua imagem socioambiental, ao invés de investirem em agências de publicidade, buscam cada vez mais se associar a organizações que atestam sua responsabilidade socioambiental e não são vistas como parte interessada, mas como representante da defesa da natureza e dos interesses coletivos (Almeida Junior \& Gomes, 2012).

Conforme Hrabanski \& Valette (2012), o referencial de serviços ambientais abriu uma janela de oportunidade na agenda política internacional. O referencial de serviços ambientais, assim atrai uma grande receptividade de atores, os quais têm a oportunidade de desempenharem o papel de mediadores deste referencial, aproveitando, cada um ao seu modo, esta janela de oportunidade. Nossos resultados demostram firmemente que os projetos estudados não surgem para reconhecer, apoiar e valorizar as múltiplas funções da agricultura com vistas ao desenvolvimento rural. Assim, concordamos com Corbera et al. (2007), em estudo dos projetos de PSA na Mesoamérica, que revelam que a emergência de tais projetos corre o risco de beneficiar somente as organizações ambientalistas bem estabelecidas, sem envolver populações locais em esforços de conservação, ou combater as desigualdades socioambientais em localidades rurais. 


\section{Considerações finais}

As origens dos projetos de PSA-Água mostram que derivaram da presença de três elementos centrais: capacidade técnica, interesse do poder político e aporte financeiro. Estes elementos se inter-relacionaram na trajetória de existência dos projetos.

O primeiro elemento imprescindível foi o envolvimento do corpo técnico para formular, gerir e executar o dispositivo de PSA-Água. Este corpo técnico teve a capacidade de influenciar e ser influenciado no campo das escolhas políticas.

Em seguida, a implantação de PSA-Água se concretizou quando o poder político foi capaz de dar existência legal e mobilizar recursos financeiros para os projetos. Tais elementos inter-relacionados foram influenciados permanentemente por atores externos aos contextos institucionais nos quais os projetos emergem, principalmente associados a organizações ambientalistas internacionais e nacionais. No entanto, nas distintas trajetórias dos dispositivos, os proprietários rurais não figuraram como atores centrais para a origem dos projetos. Apesar de serem imprescindíveis aos projetos de PSA-Água, estiveram de fora dos processos que determinaram sua existência e sua gestão.

Neste quadro, foram identificados três tipos de atores que estiveram presentes nos processos de formulação, gestão e execução dos projetos: os atores técnicos, os atores políticos e os atores parceiros. Os atores técnicos possuíram a capacidade de formular, gerir e executar os projetos, mas foram os atores políticos que tiveram em última instância o poder de decisão para sua implantação, permitindo sua viabilidade prática. Assim, foi a conjunção da capacidade técnica e do poder político em diferentes níveis de decisão que permitiu a consistência técnica e a existência legal destes projetos.

Ademais, os atores parceiros, com relevância central para as ONGs ambientalistas, influenciaram todos estes processos e viabilizaram a existência e a continuidade dos projetos. Porém, se o Estado apresentou relações estreitas com certos atores privados (as ONGs parceiras), os proprietários rurais - com interesses diretos nos projetos - estiveram ausentes do grupo considerado como atores parceiros. De fato, os atores vinculados a instituições construídas para a proteção e a recuperação ambiental estiveram impregnados de uma visão unidimensional para aplicar tal dispositivo de política pública. A concepção e execução dos projetos de PSA-Água muito pouco se alimentou de uma perspectiva de valorização da multifuncionalidade da agricultura.

De algum modo, a não inserção dos proprietários rurais no processo de formulação e implementação dos projetos pode ser examinada a partir dos interesses que moveram os atores institucionais. A realização do projeto ProdutorES de Água na Bacia do Rio Benevente fundou-se em uma estratégia de visibilidade política graças à ativação de um mercado de serviços ambientais, tendo sido encarado como um desafio a ser alcançado pelos gestores públicos. O projeto Conservador das Águas foi concebido para viabilizar a restauração florestal em propriedades privadas, utilizando o pagamento financeiro, para ter os proprietários rurais como aliados, para a sustentação do projeto. O Projeto Piloto visou implementar um princípio inovador para a gestão dos recursos hídricos, mas o acúmulo de expertise ambiental, a crescente visibilidade institucional e, por consequência, o poder de influência se apresentam, seguramente, como interesses maiores 
do conjunto de atores considerados. Portanto, apesar dos projetos de PSA-Água proporem objetivos de reconhecer, incentivar e apoiar proprietários rurais pela e para a conservação ambiental no espaço rural, não foi esta perspectiva que moveu em primeiro lugar os atores para a construírem os projetos.

Neste ponto, uma última análise dos resultados dos projetos nos parece pertinente. Em termos de impacto sobre os serviços ambientais, o ProdutorES de Água pode ser considerado nada efetivo, o Conservador das Águas foi efetivo e o Projeto Piloto foi pouco efetivo. Em termos de ganhos institucionais, todos foram efetivos. O ProdutorES de Água viabilizou a ampliação e o aperfeiçoamento de instrumentos de planejamento e gestão ambiental no estado do Espírito Santo. O Conservador das Águas possibilitou a ampliação dos recursos humanos e financeiros, além da infraestrutura, equipamentos e patrimônio da Prefeitura Municipal de Extrema. O Projeto Piloto garantiu a visibilidade institucional e $\mathrm{o}$ acúmulo de experiência às instituições envolvidas. Além destes frutos, todos ganharam experiência em termos de aplicação do mecanismo de PSA-Água no Brasil e visibilidade por serem os pioneiros na implementação deste dispositivo inovador. Em suma, além das dimensões sociais, econômicas e culturais da população rural terem sido em grande medida desconsideradas, com o privilégio da dimensão ambiental, esta última parece também não ter sido adequadamente tratada. De todo modo, são os significativos resultados institucionais alcançados que permitem explicar o engajamento dos atores para empreenderem o mecanismo de PSA-Água.

\section{Agradecimentos}

À Fundação de Amparo à Pesquisa do Estado de São Paulo e ao Conselho Nacional de Desenvolvimento Científico e Tecnológico pelo apoio financeiro à pesquisa.

\section{Referências}

ANA - Agência Nacional de Águas. Portaria n. ${ }^{\circ} 196$, de 30 de agosto de 2013. Disponível em: $<$ http://produtordeagua. ana.gov.br >. Acesso em: jan. 2013.

Almeida Junior, A. R.; Gomes, H. L. R. M. Gestão ambiental e interesses corporativos: imagem ambiental ou novas relações com o ambiente? Ambiente \& Sociedade, 15, 157-177, 2012. doi: 10.1590/S1414-753X2012000100011

Berger, P. L.; Luckmann, T. A construção social da realidade. Petrópolis: Vozes, 34. ed., 2012.

Bonnal, P.; Bonin, M.; Aznar, O. Les évolutions inversées de la multifonctionnalité de l'agriculture et des services environnementaux. VertigO, 12(3), 1-12, 2012. doi: 10.4000/ vertigo. 12882

Carneiro, M. J.; Maluf, R. S. (Orgs.). Para além da produção: multifuncionalidade e agricultura familiar. Rio de Janeiro: Mauad X, 2003.

Carneiro, M. S. ONGs, expertise e o mercado do desenvolvimento sustentável: a certificação florestal na Amazônia brasileira. Novos Cadernos NAEA, 9, 131-160, 2006. doi: $10.5801 / \mathrm{S} 21797536$

Cazella, A. A.; Bonnal, P.; Maluf, S. R. Multifuncionalidade da agricultura familiar no Brasil e enfoque de pesquisa. In: Cazella, A. A.; Bonnal, P.; Maluf, S. R. (Orgs.). Agricultura familiar: multifuncionalidade e desenvolvimento territorial no Brasil. Rio de Janeiro: Mauad X, p. 47-70, 2009.

Chiodi, R. E.; Puga, B. P.; Sarcinelli, O. Análise institucional do mecanismo de pagamento por serviços ambientais: o Projeto Conservador das Águas em Extrema - MG. Revista de Políticas Públicas, 17, 37-47, 2013. doi: 10.18764/2178- 
2865.v17n1p37-47

Corbera, E.; Kosoy, N.; Tuna, M. M. Equity implications of marketing ecosystem services in protected areas and rural communities: Case studies from Meso-America. Global Environmental Change, 17, 365-380, 2007. doi: 10.1016/j. gloenvcha.2006.12.005

Daily, G. C. Nature's services: societal dependence on natural ecosystems. Washington: Island Press, 1997.

Diegues, A. C. A ecologia política das grandes ONGS transnacionais conservacionistas. São Paulo: NUPAUB/ USP, 2008.

Engel, S.; Pagiola, S.; Wunder, S. Designing payments for environmental services in theory and practice: An overview of the issues. Ecological Economics, 65, 663-674, 2008. doi: 10.1016/j.ecolecon.2008.03.011

Espírito Santo. Lei $n .^{\circ} 8.995$, de 22 de setembro de 2008. Institui o Programa de Pagamento por Serviços Ambientais PSA e dá outras providências. Vitória: DOE de 23/09/2008.

Extrema. Lei $n .^{\circ} 2.100$, de 21 de dezembro de 2005. Cria o Projeto Conservador das Águas. Extrema: DO de 21/12/2005.

Extrema. Projeto Conservador das Águas 10 anos, 2015. Disponível em: http://extrema.mg.gov.br/conservadordasaguas/CONSERVADOR_PDF_leitura.pdf. Acesso em: jan. 2016.

Grisa, C. As ideias na produção de políticas públicas: contribuições da abordagem cognitiva. In: Bonnal, P.; Leite, S. P. (Orgs.). Análise comparada de políticas agrícolas: uma agenda em transformação. Rio de Janeiro: Maud X, p. 93-137, 2011.

Hrabanski, M.; Valette, E. Organisations environnementales et services écosystémiques: stratégies de difusion du concept et opportunités politiques. VertigO, 12(3), 1-13, 2012. doi: 10.4000/vertigo. 12904

Jobert, B.; Muller, P. L'état em action. Paris: PUF, 1987.

Kalaora, B. Global expert: la religion des mots. Ethnologie française, 29, 513-527, 1999.

Kosoy, N.; Corbera, E. Payments for ecosystem services as commodity fetishism. Ecological Economics, 69, 1228-
1236, 2010. doi: 10.1016/j.ecolecon.2009.11.002

Lakatos, E. V.; Marconi, M. A. Fundamentos de metodologia científica. São Paulo: Editora Atlas, 3. ed., 1991.

Maluf, R. S. O enfoque da multifuncionalidade da agricultura: aspectos analíticos e questões de pesquisa. In: Lima, D. M.; Wilkinson, J. (Orgs.). Inovação nas tradições da agricultura familiar. Brasília: CNPq/Paralelo 15, p. 301328, 2002.

Marques, E. Rede sociais, instituições e atores políticos no governo da cidade de São Paulo. São Paulo: Annablume, Fapesp, 2003.

Massardier, G. Cognição, políticas e ações públicas: entre coerência, fragmentação e aprendizados. In: Bonnal, P.; Leite, S. P. (Orgs.). Análise comparada de políticas agrícolas: uma agenda em transformação. Rio de Janeiro: Mauad X, p. 69-91, 2011.

MEA - Millenium Ecosystem Assessment. Ecosystem and human well-being: synthesis, 2005. Disponível em: <www. millenniumassessment.org/documents/document.356.aspx. pdf $>$

Mormont, M. As ruralidades nas políticas globais. Desenvolvimento e Meio Ambiente, 34, 49-59, 2015. doi: 10.5380/ dma.v34i0.39940

Muller, P. Las políticas públicas. Colômbia: Universidad Externado, 2002.

Muradian, R.; Corbera, E.; Pascual, U.; Kosoy, N.; May, P. Reconciling theory and practice: An alternative conceptual framework for understating payments for environmental services. Ecological Economics, 69, 1202-1208, 2010. doi: 10.1016/j.ecolecon.2009.11.006

Nierdele, P. A.; Grisa, C. Ideias e valores: a análise da ação pública a partir das interfaces entre a abordagem cognitiva e a economia das convenções. Política \& Sociedade, 12, 97-136, 2013. doi: 10.5007/2175-7984.2013v12n23p97

Padovezi, A.; Viani, R. A. G.; Kubota, U.; Taffarelo, D.; Faria, M.; Bracale, H.; Ferrati, V.; Carvalho, F. H. Produtor de Água na Bacia Hidrográfica Piracicaba, Capivari e Jundiaí. In: Pagiola, S.; Glehn, H. C.; Taffarello, D. (Orgs.). 
Experiências de pagamento por serviços ambientais no Brasil. São Paulo: SMA-SP, p. 99-113, 2013.

Pagiola, S.; Glehn, H. C.; Taffarello, D. Introdução. In: Pagiola, S.; Glehn, H. C.; Taffarello, D (Orgs.). Experiências de pagamento por serviços ambientais no Brasil. São Paulo: SMA-SP, p. 17-27, 2013.

Pereira, P. H. Projeto Conservador das Águas - Extrema. In: Pagiola, S. Glehn, H. C.; Taffarello, D. (Orgs.). Experiências de pagamento por serviços ambientais no Brasil. São Paulo: SMA-SP, p. 29-40, 2013.
Sabourin, E. Implicações teóricas e epistemológicas do reconhecimento da noção de multifucionalidade da agricultura. Revista Estudos, Sociedade e Agricultura, 13, 161-189, 2005. Disponível em: http://r1.ufrrj.br/esa/V2/ojs/index. php/esa/article/view/262

Sachs, I. Desenvolvimento: includente, sustentável, sustentado. Rio de Janeiro: Garamond, 2004.

Sossai, M. F.; Aguiar, M. A.; Teixeira, C. P.; Novelli, F. Z.; Cerqueira, A. F.; Anhert, F. Políticas públicas do estado do Espírito Santo para adequação ambiental e socioeconômica de propriedades rurais como estratégia de ampliação da cobertura florestal. Informe Agropecuário, 33, 7-13, 2012. Disponível em: http://www.epamig.br/download/informe-agropecuario-271-adequacao-socioeconomica-e-ambiental-de-propriedades-rurais-2012/ 